\title{
Relationship between serum potassium level and survival outcome in out-of-hospital cardiac arrest using CAPTURES database of Korea: Does hypokalemia have good neurological outcomes in out-of-hospital cardiac arrest?
}

\author{
Dong Sun Choi ${ }^{1, A-D, F}$, Sang Do Shin ${ }^{1, A, C, E, F}$, Young Sun Ro $2, B, C, E, F$, Kyung Won Lee ${ }^{3, D-F}$ \\ 1 Department of Emergency Medicine, Seoul National University Hospital, South Korea \\ ${ }^{2}$ Biomedical Research Institute, Seoul National University Hospital, South Korea \\ ${ }^{3}$ Department of Emergency Medicine, Kyung Hee University Hospital at Gangdong, South Korea \\ A - research concept and design; $\mathrm{B}$ - collection and/or assembly of data; $\mathrm{C}$ - data analysis and interpretation; \\ $D$ - writing the article; $E$ - critical revision of the article; $F$ - final approval of the article
}

Address for correspondence

Kyung Won Lee

E-mail: emkwlee@gmail.com

Funding sources

None declared

Conflict of interest

None declared

Received on December 10, 2017

Reviewed on June 12, 2018

Accepted on May 8, 2020

Published online on July 1,2020

Cite as

Choi DS, Shin SD, Ro YS, Lee KW. Relationship between serum potassium level and survival outcome in out-of-hospital cardiac arrest using CAPTURES database of Korea: Does hypokalemia have good neurological outcomes in out-ofhospital cardiac arrest? Adv Clin Exp Med. 2020;29(6):727-734. doi:10.17219/acem/122178

DOI

10.17219/acem/122178

Copyright

Copyright by Author(s)

This is an article distributed under the terms of the

Creative Commons Attribution 3.0 Unported ( $C$ C BY 3.0)

(https://creativecommons.org/licenses/by/3.0/)

\begin{abstract}
Background. Sudden cardiac arrest is a major cause of death worldwide. Serum potassium level is an initial laboratory test that serves as part of an electrolyte panel easily obtainable by most emergency departments (EDs).

Objectives. To evaluate the relationship between serum potassium level and the survival outcome for out-of-hospital cardiac arrest (OHCA) patients.

Material and methods. We used the Cardiac Arrest Pursuit Trial with Unique Registration and Epidemiological Surveillance (CAPTURES) database, which made up the OHCA cohort of 27 EDs in Korea from January to December 2014. The inclusion criteria were all OHCA patients in the cohort who had received cardiopulmonary resuscitation (CPR) in the hospital. The patients were excluded if they were transferred from another hospital, had a pre-hospital return of spontaneous circulation (ROSC), or if the potassium level and clinical outcome data were missing or not captured. The main parameter was serum potassium level on ED arrival. According to the serum potassium level, the patients were divided into a hypokalemia group $(K+<3.5 \mathrm{mEq} / \mathrm{L})$, a normokalemia group $(K+=3.5-5.4 \mathrm{mEq} / \mathrm{L})$ and a hyperkalemia group $(K+\geq 5.5 \mathrm{mEq} / \mathrm{L})$. The primary outcome was neurologically favorable survival discharge.
\end{abstract}

Results. Among the 1,616 patients in the CAPTURES cohort, 913 patients were included in the analysis, of whom 46 patients (5.9\%) were assigned to the hypokalemia group, 370 patients (40.5\%) were assigned to the normokalemia group and 497 patients (54.4\%) were assigned to the hyperkalemia group. The hypokalemia group has a significantly higher percentage of good neurological outcomes (26.1\%). There was a significant positive correlation with neurologically favorable survival (odds ratio $(O R)=4.45 ; 95 \%$ confidence interval $(95 \%(\mathrm{Cl})=1.67-11.91)$ and a significant positive correlation with survival discharge $(\mathrm{OR}=2.25$; $95 \%(\mathrm{l}=1.05-4.82)$.

Conclusions. In OHCA patients, serum potassium level measured in the hospital showed a significant association with survival outcome. Hypokalemia had a significant association with good neurological outcome and survival discharge.

Key words: potassium, hypokalemia, resuscitation, sudden cardiac death, hyperkalemia 


\section{Introduction}

Sudden cardiac arrest is a major cause of death worldwide. In addition, the most frequent cause of out-of-hospital cardiac arrest (OHCA) is ischemic heart disease. In the USA, 38 people suffer from OHCA every hour. ${ }^{1,2}$ Over the last few decades, the continuous efforts of the emergency medical services (EMS) and improvements in the "chain of survival" have increased the survival outcome. ${ }^{3}$ However, the survival rate of OHCA varies markedly and the neurologically favorable survival rate remains low. ${ }^{1}$

Early and accurate prediction of the outcome of OHCA can help physicians improve therapeutic efforts in patients who have very good chances of surviving. Predictors of good survival outcome in OHCA patients include initial cardiac rhythm, witnesses to the event, bystander administration of cardiopulmonary resuscitation (CPR), and early defibrillation. ${ }^{4-7}$ After achieving the return of spontaneous circulation (ROSC), physicians can use clinical examination, electroencephalography (EEG) findings, evoked potentials, imaging tests, and brain-specific biomarkers - including neuron-specific enolase (NSE) and S100B - to predict the outcome in post-arrest patients. ${ }^{8-10}$ However, these biomarkers and tools are difficult to access in emergency departments (EDs) immediately after the patients arrive.

Serum potassium level is an initial laboratory test that, as part of an electrolyte panel, can be determined easily at most EDs. Potassium is a major component of internal cellular electrolytes in the body. The electrical difference between internal and external electrolytes is the membrane potential. Therefore, serum potassium level affects membrane potential and myocardial cell conduction. In cardiac arrest, the serum potassium level may influence myocardial function. Hyperkalemia decreases myocardial cell conduction velocity, and it can lead to fatal bradyarrhythmia and cardioplegia. Several observation studies show that hyperkalemia can be associated with poor survival outcome. ${ }^{11,12}$ Hypokalemia increases conduction velocity. In patients with acute myocardial infarction (AMI), several observation studies show that hypokalemia is associated with arrhythmia and increased mortality. ${ }^{13,14}$ Due to these effects, serum potassium level can be an early predictor of survival outcomes.

We conducted this study to evaluate serum potassium level as a predictor of OHCA. We hypothesized that the OHCA patients with normokalemia have better survival outcomes than those with hypokalemia or hyperkalemia.

\section{Material and methods}

\section{Study design and data source}

This retrospective observational study made use of the Cardiac Arrest Pursuit Trial with Unique Registration and Epidemiologic Surveillance (CAPTURES) database in Korea. The CAPTURES project was conducted from January to December 2014 on OHCA patients who visited 27 EDs (9 level 1 EDs and 18 level 2 EDs).

The purpose of the CAPTURES project was to identify the risk factors for $\mathrm{OHCA}$ and to investigate the prognostic factors. All OHCA patients who visited the participating EDs were included in the CAPTURES project if they received prehospital $C P R$ via EMS and their cardiogenic cardiac arrest was verified by an emergency physician. This study excluded terminal-stage patients, hospice patients, pregnant patients, patients without legal guardians who could provide patient information, homeless patients, and patients with "do not resuscitate" orders. Patients with cardiac arrest caused by apparent trauma, drowning, addiction, burns, or choking were also excluded from the study.

The CAPTURES registry collected information on these patients, such as their socioeconomic status, health, previous medical history, physical or mental stress, Utstein-style prehospital and hospital stage report, hematological examination results, and short-term and long-term results. Emergency physicians of the participating hospitals conducted face-to-face interviews with the patients or the patients' families. The study coordinators obtained the first hematological examination results after the patients' arrival at the ED and cardiac examination results from the medical record, and they collected six-month and twelve-month results of the patients via telephone if the patients survived and were discharged. All data was stored in a server using EpiData v. 3.1 (www.epidata.dk). The collected data was reviewed monthly by a quality management committee, consisting of emergency physicians, preventative medicine physicians and cardiologists of hospitals they had attended, where feedback on the collected data coding was given to the coordinators. ${ }^{15}$

\section{Setting and study subjects}

Emergency medical services in Korea form a singletier, government-based system which provides a basic-tointermediate level of ambulance service in 16 provincial headquarters of the national fire department and serves a population of about 50 million people. ${ }^{15,16}$ The ambulance personnel cannot declare death at the scene or terminate CPR unless there is a ROSC. Therefore, all patients with OHCA are transported to the ED. ${ }^{17}$ All EDs in Korea are designated as level 1, 2 or 3 by the government in which the level designation is based on human resources, intensive care units (ICUs), instruments, and equipment available at each ED. Level $1(n=19)$ and level $2(n=110)$ EDs have more resources and better facilities for emergency care and they must be staffed by emergency physicians $24 \mathrm{~h}$ a day. All EDs are subject to an annual evaluation by a governmental audit committee. The patients eligible for this study (older than 18 years of age) were all EMStreated $\mathrm{OHCA}$ patients with presumed cardiac etiology who were transported to participating EDs from January 
to December 2014. The patients who achieved prehospital ROSC, who were transferred from another hospital or whose initial serum potassium levels were not recorded were excluded from the study.

Patients who arrived at the ER received CPR based on the recommendation of the 2010 American Heart Association (AHA) guideline of advanced cardiovascular life support. ${ }^{18}$ Laboratory tests, including arterial blood gas analysis, were routinely performed on arrival.

\section{Measurements}

The primary outcome was neurologically favorable survival at hospital discharge, defined a priori as a GlasgowPittsburgh Cerebral Performance Category (CPC) of 1 or $2 .{ }^{19}$ The CPC was estimated based on a medical record review. The secondary outcome was survival hospital discharge.

\section{Variables}

The main parameter was serum potassium level on arrival to the ED. The patients were divided into groups according to their serum potassium levels: a hypokalemia group $\left(\mathrm{K}^{+}<3.5 \mathrm{mEq} / \mathrm{L}\right)$, a normokalemia group $\left(\mathrm{K}^{+}=3.5-\right.$ $5.4 \mathrm{mEq} / \mathrm{L})$ and a hyperkalemia group $\left(\mathrm{K}^{+} \geq 5.5 \mathrm{mEq} / \mathrm{L}\right)$. We collected the initial laboratory test results from the ED (serum levels of sodium, chloride, creatinine, and blood urea nitrogen (BUN), and arterial blood gas analysis (ABGA) of $\mathrm{pH}$, partial pressure of carbon dioxide $\left(\mathrm{PaCO}_{2}\right)$, partial pressure of oxygen $\left(\mathrm{PaO}_{2}\right)$, and oxygen saturation $\left.\left(\mathrm{SaO}_{2}\right)\right)$. Patients with a creatinine level higher than 1.5 were defined as renally impaired patients. Severe metabolic acidosis was defined as an arterial serum $\mathrm{pH}$ level of less than 7.2.

We collected the Utstein-defined covariates, which include gender, age, presence of a witness, bystander CPR, initial electrocardiography (ECG) rhythm, prehospital defibrillation, arrest location, time elapsed from call to ambulance arrival at the scene (EMS response time), time elapsed from arrival at the scene to departure (EMS on-scene time), time elapsed from departure to arrival at the ED (EMS transport time), and level of the ED (level 1 or 2). The time at which the cardiac arrest occurred or the time estimated by an emergency medical technician (EMT) was recorded. In addition, the cardiac arrest to ED arrival time was calculated as the interval from when the cardiac arrest occurred to the hospital arrival time. Previous medical history of diabetes mellitus (DM) and hypertension and treatment method (pharmacotherapy or non-pharmacotherapy) was collected using a survey. ${ }^{15}$

\section{Statistical analysis}

We compared the patient demographics and arrest characteristics among the hypokalemia, normokalemia and hyperkalemia groups using $X^{2}$ test for the categorical variable and the Kruskal-Wallis test for the continuous variable. We performed post hoc analysis to compare groups, using $\chi^{2}$ test with Bonferroni correction for the categorical variable and Dunn's test for the continuous variable. A univariate logistic regression analysis was conducted in order to estimate the association between potassium level and survival outcome. In order to test the collinearity problem, the condition index was applied.

Serum $\mathrm{pH}$ had a large effect on the survival outcome. When the serum pH level was included, the condition index was determined to be over 30 . Therefore, we divided the serum $\mathrm{pH}$ level into severe metabolic acidosis $(\mathrm{pH}<7.2)$ and non-severe metabolic acidosis ( $\mathrm{pH} \geq 7.2)$. Hypoxia was defined as a $\mathrm{SaO}_{2}$ level lower than $90 \%$. Multivariate logistic regression analysis was conducted in order to calculate the adjusted odd ratios (ORs) and 95\% confidence intervals (95\% CIs) after adjusting for potential confounding variables, including age, gender, primary ECG type, etiology of arrest, presence of a witness, bystander CPR, arrest to ED arrival time, prehospital defibrillation, hypoxia, severe metabolic acidosis, DM, and hypertension. Fully conditional specification (FCS) method was applied for imputing missing values of the arrest to ED arrival time $(\mathrm{n}=59)$, DM $(\mathrm{n}=82)$, hypertension $(\mathrm{n}=79)$, severe acidosis $(\mathrm{n}=37)$, and hypoxia $(\mathrm{n}=141)$. The analysis was performed using SAS software v. 9.4 for Windows (SAS Institute, Cary, USA).

\section{Results}

During the study period, there were 1,616 EMS-treated OHCA patients in the CAPTURES database. We excluded 703 patients according to the study criteria and analyzed the remaining 913 patients (Fig. 1). In the total study group, the median potassium level was $5.7 \mathrm{mEq} / \mathrm{L}$ (interquartile range $(\mathrm{IQR})=4.5-7.1)$. Among the 913 patients, 46 (5.0\%) were assigned to the hypokalemia group, 370 patients (40.5\%) were assigned to the normokalemia group and 497 (54.4\%) were assigned to the hyperkalemia group (Fig. 1). The demographics and arrest characteristics of this study population are summarized in Table 1 . The neurologically favorable survival rates were $4.5 \%$ in the total study population, $26.1 \%$ in the hypokalemia group, $5.7 \%$ in the normokalemia group, and $1.6 \%$ in the hyperkalemia group (Table 1). There were no patients with neurologically favorable survival at discharge when the serum potassium level was higher than $7.0 \mathrm{mEq} / \mathrm{L}$.

Table 2 shows the initial laboratory test results of each group. The hyperkalemia group had a significantly higher creatinine level than that of the other groups $(\mathrm{p}<0.05)$. The median creatinine level was $1.5 \mathrm{mg} / \mathrm{dL}$ (IQR $=1.1-$ $2.63 \mathrm{mg} / \mathrm{dL}$ ) in the hyperkalemia group, $1.26 \mathrm{mg} / \mathrm{dL}$ (IQR $=1.03-1.53 \mathrm{mg} / \mathrm{dL})$ in the normokalemia group and $1.23 \mathrm{mg} / \mathrm{dL}(\mathrm{IQR}=0.98-1.58 \mathrm{mg} / \mathrm{dL})$ in the hypokalemia group. The hyperkalemia group has a significantly lower 
Table 1. Demographics of out-of-hospital cardiac arrest patients according to initial serum potassium level

\begin{tabular}{|c|c|c|c|c|c|c|c|c|c|}
\hline \multirow{2}{*}{ Variables } & \multicolumn{2}{|c|}{ Total } & \multicolumn{2}{|c|}{ Hypokalemia } & \multicolumn{2}{|c|}{ Normokalemia } & \multicolumn{2}{|c|}{ Hyperkalemia } & \multirow{2}{*}{$p$-value } \\
\hline & $\bar{N}$ & $\%$ & $\bar{N}$ & $\%$ & $\bar{N}$ & $\%$ & $\bar{N}$ & $\%$ & \\
\hline Total & 913 & & 46 & & 370 & & 497 & & \\
\hline $\begin{array}{l}\text { Age [years] } \\
\text { 18-64 } \\
65-74 \\
75+ \\
\text { median }\end{array}$ & $\begin{array}{c}372 \\
209 \\
332 \\
69\end{array}$ & $\begin{array}{c}40.7 \\
22.9 \\
36.4 \\
55-78\end{array}$ & $\begin{array}{c}27 \\
10 \\
9 \\
58.5\end{array}$ & $\begin{array}{c}58.7 \\
21.7 \\
19.6 \\
46-73\end{array}$ & $\begin{array}{c}173 \\
84 \\
113 \\
66\end{array}$ & $\begin{array}{c}46.8 \\
22.7 \\
30.5 \\
53-76\end{array}$ & $\begin{array}{c}172 \\
115 \\
210 \\
72\end{array}$ & $\begin{array}{c}34.6 \\
23.1 \\
42.3 \\
57-79\end{array}$ & $\begin{array}{l}0.0001^{b c} \\
0.0085^{e f}\end{array}$ \\
\hline $\begin{array}{l}\text { Gender } \\
\text { male }\end{array}$ & 621 & 68.0 & 39 & 84.8 & 247 & 66.8 & 335 & 67.4 & $0.0429^{a b}$ \\
\hline $\begin{array}{l}\text { Underlying HTN } \\
\text { HTN without medication } \\
\text { HTN with medication }\end{array}$ & $\begin{array}{c}54 \\
315\end{array}$ & $\begin{array}{c}5.9 \\
34.5\end{array}$ & $\begin{array}{c}4 \\
16\end{array}$ & $\begin{array}{c}8.7 \\
34.8\end{array}$ & $\begin{array}{c}17 \\
126\end{array}$ & $\begin{array}{c}4.6 \\
34.1\end{array}$ & $\begin{array}{c}33 \\
173\end{array}$ & $\begin{array}{c}6.6 \\
34.8\end{array}$ & 0.6212 \\
\hline $\begin{array}{l}\text { Underlying DM } \\
\text { yes }\end{array}$ & 222 & 24.3 & 13 & 28.3 & 68 & 18.4 & 141 & 28.4 & $0.0013^{c}$ \\
\hline $\begin{array}{l}\text { Prehospital shockable rhythm } \\
\text { yes }\end{array}$ & 189 & 20.7 & 22 & 47.8 & 121 & 32.7 & 46 & 9.3 & $<0.0001^{b c}$ \\
\hline $\begin{array}{l}\text { Witnessed arrest } \\
\text { yes }\end{array}$ & 590 & 64.6 & 34 & 73.9 & 262 & 70.8 & 294 & 59.2 & $0.0007^{c}$ \\
\hline $\begin{array}{l}\text { Bystander CPR } \\
\text { yes }\end{array}$ & 379 & 41.5 & 23 & 50.0 & 162 & 43.8 & 194 & 39.0 & 0.1819 \\
\hline $\begin{array}{l}\text { Public location } \\
\text { yes }\end{array}$ & 230 & 25.2 & 15 & 32.6 & 108 & 29.2 & 107 & 21.5 & $0.0182^{c}$ \\
\hline $\begin{array}{l}\text { EMS defibrillation } \\
\text { yes }\end{array}$ & 214 & 23.4 & 21 & 45.7 & 127 & 34.3 & 66 & 13.3 & $<0.0001^{b c}$ \\
\hline $\begin{array}{l}\text { Response time interval } \\
\text { missing } \\
0-4 \text { min } \\
4-8 \text { min } \\
8-12 \text { min } \\
12-16 \text { min } \\
>16 \text { min } \\
\text { median (IQR) }\end{array}$ & $\begin{array}{c}6 \\
75 \\
484 \\
249 \\
58 \\
41 \\
6\end{array}$ & $\begin{array}{c}0.7 \\
8.2 \\
53.0 \\
27.3 \\
6.4 \\
4.5 \\
5-9\end{array}$ & $\begin{array}{c}2 \\
3 \\
28 \\
10 \\
2 \\
1 \\
6\end{array}$ & $\begin{array}{c}4.3 \\
6.5 \\
60.9 \\
21.7 \\
4.3 \\
2.2 \\
5-8\end{array}$ & $\begin{array}{c}3 \\
30 \\
206 \\
104 \\
16 \\
11 \\
6\end{array}$ & $\begin{array}{c}0.8 \\
8.1 \\
55.7 \\
28.1 \\
4.3 \\
3.0 \\
5-9\end{array}$ & $\begin{array}{c}1 \\
42 \\
250 \\
135 \\
40 \\
29 \\
6\end{array}$ & $\begin{array}{c}0.2 \\
8.5 \\
50.3 \\
27.2 \\
8.0 \\
5.8 \\
5-10\end{array}$ & $\begin{array}{l}0.1555 \\
0.1304\end{array}$ \\
\hline $\begin{array}{l}\text { Scene time interval } \\
\text { missing } \\
0-4 \text { min } \\
4-8 \text { min } \\
8-12 \mathrm{~min} \\
12-16 \mathrm{~min} \\
>16 \mathrm{~min} \\
\text { median (IQR) }\end{array}$ & $\begin{array}{c}17 \\
144 \\
337 \\
281 \\
73 \\
61 \\
7\end{array}$ & $\begin{array}{c}1.9 \\
15.8 \\
36.9 \\
30.8 \\
8.0 \\
6.7 \\
5-10\end{array}$ & $\begin{array}{c}3 \\
5 \\
15 \\
13 \\
4 \\
6 \\
8\end{array}$ & $\begin{array}{c}6.5 \\
10.9 \\
32.6 \\
28.3 \\
8.7 \\
13.0 \\
5-10\end{array}$ & $\begin{array}{c}7 \\
62 \\
127 \\
115 \\
29 \\
30 \\
7\end{array}$ & $\begin{array}{c}1.9 \\
16.8 \\
34.3 \\
31.1 \\
7.8 \\
8.1 \\
4-11\end{array}$ & $\begin{array}{c}7 \\
77 \\
195 \\
153 \\
40 \\
25 \\
7\end{array}$ & $\begin{array}{c}1.4 \\
15.5 \\
39.2 \\
30.8 \\
8.0 \\
5.0 \\
5-10\end{array}$ & 0.3653 \\
\hline $\begin{array}{l}\text { Transport time interval } \\
\text { missing } \\
0-4 \text { min } \\
4-8 \text { min } \\
8-12 \text { min } \\
12-16 \text { min } \\
>16 \text { min } \\
\text { median (IQR) }\end{array}$ & $\begin{array}{c}15 \\
59 \\
304 \\
269 \\
123 \\
143 \\
123\end{array}$ & $\begin{array}{c}1.6 \\
6.5 \\
33.3 \\
29.5 \\
13.5 \\
15.7 \\
6-14\end{array}$ & $\begin{array}{c}1 \\
3 \\
19 \\
12 \\
3 \\
8 \\
3\end{array}$ & $\begin{array}{c}2.2 \\
6.5 \\
41.3 \\
26.1 \\
6.5 \\
17.4 \\
5-11\end{array}$ & $\begin{array}{c}7 \\
25 \\
133 \\
100 \\
48 \\
57 \\
48\end{array}$ & $\begin{array}{c}1.9 \\
6.8 \\
35.9 \\
27.0 \\
13.0 \\
15.4 \\
5.5-13\end{array}$ & $\begin{array}{c}7 \\
31 \\
152 \\
157 \\
72 \\
78 \\
72\end{array}$ & $\begin{array}{c}1.4 \\
6.2 \\
30.6 \\
31.6 \\
14.5 \\
15.7 \\
6-14\end{array}$ & $\begin{array}{l}0.5640 \\
0.1304\end{array}$ \\
\hline $\begin{array}{l}\text { Arrest to ED arrival time } \\
\text { missing } \\
0-15 \text { min } \\
15-30 \text { min } \\
>30 \text { min } \\
\text { median (IQR) }\end{array}$ & $\begin{array}{c}59 \\
89 \\
405 \\
360 \\
27\end{array}$ & $\begin{array}{c}6.5 \\
9.7 \\
44.4 \\
39.4 \\
21-36\end{array}$ & $\begin{array}{c}2 \\
4 \\
26 \\
14 \\
25\end{array}$ & $\begin{array}{c}4.3 \\
8.7 \\
56.5 \\
30.4 \\
20-33\end{array}$ & $\begin{array}{c}15 \\
48 \\
176 \\
131 \\
26\end{array}$ & $\begin{array}{c}4.1 \\
13.0 \\
47.6 \\
35.4 \\
20-33\end{array}$ & $\begin{array}{c}42 \\
37 \\
203 \\
215 \\
28\end{array}$ & $\begin{array}{c}8.5 \\
7.4 \\
40.8 \\
43.3 \\
21.5-40\end{array}$ & $\begin{array}{l}0.0065^{c} \\
0.0009\end{array}$ \\
\hline $\begin{array}{l}\text { ED level } \\
\text { level } 1 \\
\text { level } 2\end{array}$ & $\begin{array}{l}400 \\
513\end{array}$ & $\begin{array}{l}43.8 \\
56.2\end{array}$ & $\begin{array}{l}17 \\
29\end{array}$ & $\begin{array}{l}37.0 \\
63.0\end{array}$ & $\begin{array}{l}166 \\
204\end{array}$ & $\begin{array}{l}44.9 \\
55.1\end{array}$ & $\begin{array}{l}217 \\
280\end{array}$ & $\begin{array}{l}43.7 \\
56.3\end{array}$ & 0.5917 \\
\hline $\begin{array}{l}\text { Survival outcome } \\
\text { ROSC } \\
\text { survival discharge } \\
\text { good neurological outcome }\end{array}$ & $\begin{array}{c}412 \\
88 \\
41\end{array}$ & $\begin{array}{c}45.1 \\
9.6 \\
4.5\end{array}$ & $\begin{array}{l}35 \\
15 \\
12\end{array}$ & $\begin{array}{l}76.1 \\
32.6 \\
26.1\end{array}$ & $\begin{array}{l}185 \\
53 \\
21 \\
\end{array}$ & $\begin{array}{c}50.0 \\
14.3 \\
5.7\end{array}$ & $\begin{array}{c}192 \\
20 \\
8\end{array}$ & $\begin{array}{c}38.6 \\
4.0 \\
1.6\end{array}$ & $\begin{array}{l}<0.0001^{a b c} \\
<0.0001^{a b c} \\
<0.0001^{a b c}\end{array}$ \\
\hline
\end{tabular}

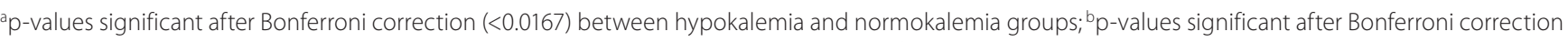
$(<0.0167)$ between hypokalemia and hyperkalemia groups; ${ }^{c} p$-values significant after Bonferroni correction $(<0.0167)$ between normokalemia and hyperkalemia groups; ${ }^{d}$ significant difference in Dunn's test $(a=0.05)$ between hypokalemia and normokalemia groups; ${ }^{e}$ significant difference in Dunn's test $(a=0.05)$ between hypokalemia and hyperkalemia groups; ${ }^{f}$ significant difference in Dunn's test $(a=0.05)$ between normokalemia and hyperkalemia groups. HTN - hypertension; DM - diabetes mellitus; IQR - interquartile range; CPR - cardiopulmonary resuscitation; EMS - emergency medical services; ED - emergency department; ROSC - return of spontaneous circulation. 


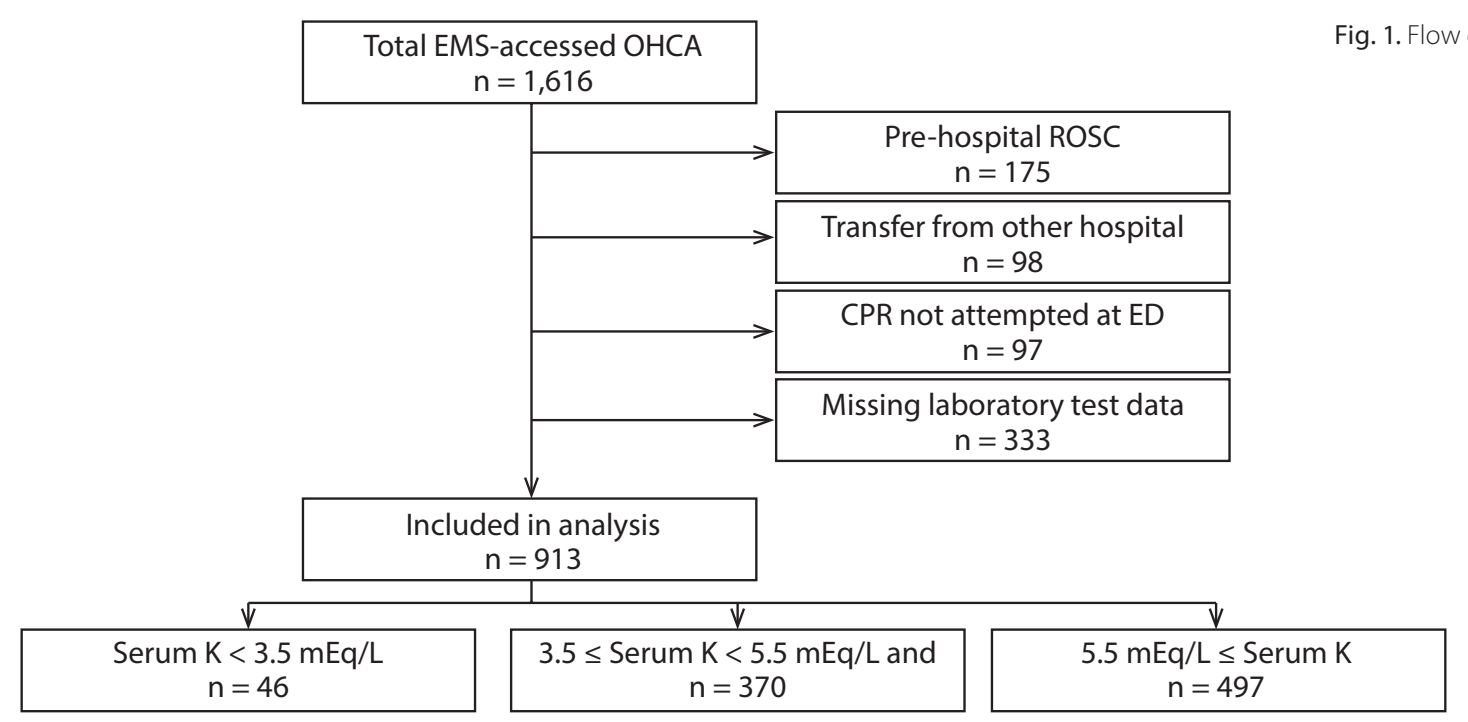

Table 2. Biochemical parameters of out-of-hospital cardiac arrest patients according to initial serum potassium level

\begin{tabular}{|c|c|c|c|c|c|}
\hline Parameter & $\begin{array}{c}\text { Total } \\
\text { median (IQR) }\end{array}$ & $\begin{array}{l}\text { Hypokalemia } \\
\text { median (IQR) }\end{array}$ & $\begin{array}{l}\text { Normokalemia } \\
\text { median (IQR) }\end{array}$ & $\begin{array}{l}\text { Hyperkalemia } \\
\text { median (IQR) }\end{array}$ & $p$-value \\
\hline $\mathrm{Na}[\mathrm{mmol} / \mathrm{L}]$ & $140(136-144)$ & $140.8(138-145)$ & 141 (138-144.4) & $139(134-143)$ & $<0.0001^{a}$ \\
\hline $\mathrm{Cl}[\mathrm{mmol} / \mathrm{L}]$ & 103 (99-106) & $104(99-108)$ & $103.4(100.6-107)$ & $102(97-106)$ & $0.0004^{a}$ \\
\hline BUN [mg/dL] & $19(14.2-30)$ & $15(12.1-20.5)$ & $17(13-22.3)$ & $23(16-45.35)$ & $<0.0001 \mathrm{a}, \mathrm{b}$ \\
\hline $\mathrm{Cr}[\mathrm{mg} / \mathrm{dL}]$ & $1.38(1.09-1.9)$ & $1.23(0.98-1.58)$ & $1.26(1.03-1.53)$ & $1.5(1.1-2.63)$ & $<0.0001 \mathrm{a}, \mathrm{b}$ \\
\hline $\mathrm{pH}$ & $6.97(6.85-7.09)$ & 7.07 (6.98-7.23) & $7.02(6.9-7.12)$ & $6.92(6.81-7.03)$ & $<0.0001$ a,b,c \\
\hline $\mathrm{PaCO}_{2}[\mathrm{~mm} \mathrm{Hg}]$ & $73(53-92)$ & $53.1(33-77)$ & $73(55-87.7)$ & $74(53-16.0)$ & $<0.0001^{a, c}$ \\
\hline $\mathrm{PaO}_{2}[\mathrm{~mm} \mathrm{Hg}]$ & $33.8(16-67)$ & $65(28-92)$ & $29.1(14-69)$ & $35.5(17-61.8)$ & $0.0044^{a, b}$ \\
\hline $\mathrm{SaO}_{2}[\%]$ & $38.6(12.25-81.4)$ & 77 (30.4-95) & $33.1(11.3-81.7)$ & $39.4(12.4-76.6)$ & $0.0011^{a, b}$ \\
\hline $\mathrm{HCO}_{3}[\mathrm{mEq} / \mathrm{L}]$ & $16.65(12.4-21.4)$ & $16.1(12-21.7)$ & $18(13.9-22.2)$ & $16(11.7-20.3)$ & $<0.0001 \mathrm{a}, \mathrm{b}, \mathrm{c}$ \\
\hline
\end{tabular}

${ }^{a}$ significant difference in Dunn's test $(a=0.05)$ between hypokalemia and normokalemia groups; ${ }^{b}$ significant difference in Dunn's test $(a=0.05)$ between hypokalemia and hyperkalemia groups; ${ }^{\circ}$ significant difference in Dunn's test $(a=0.05)$ between normokalemia and hyperkalemia groups. IQR - interquartile range; $\mathrm{Cr}$ - creatinine; $\mathrm{BUN}$ - blood urea nitrogen; $\mathrm{PaCO}_{2}$ - partial pressure of carbon dioxide; $\mathrm{PaO}_{2}$ - partial pressure of oxygen; $\mathrm{SaO}_{2}$ - oxygen saturation.

$\mathrm{pH}$ than the other groups $(\mathrm{p}<0.05)$. The median $\mathrm{pH}$ level is $6.92 \mathrm{mg} / \mathrm{dL}(\mathrm{IQR}=6.81-7.03)$ in the hyperkalemia group, $7.02 \mathrm{mg} / \mathrm{dL}(\mathrm{IQR}=6.9-7.12)$ in the normokalemia group and $7.07 \mathrm{mg} / \mathrm{dL}$ (IQR = 6.98-7.23) in the hypokalemia group. The hypokalemia group had a significantly lower $\mathrm{PaCO}_{2}$ level than the other groups $(\mathrm{p}<0.05)$.

The relationship between serum potassium level and survival outcome is shown in Table 3. After adjusting the covariates, hypokalemia had a significantly positive correlation with neurologically favorable survival $(\mathrm{OR}=4.45 ; 95 \% \mathrm{CI}=1.67-11.91 ; \mathrm{p}=0.0012)$ and survival discharge $(\mathrm{OR}=2.25 ; 95 \% \mathrm{CI}=1.05-4.82 ; \mathrm{p}=0.0011)$. Furthermore, the hyperkalemia group had no statistically significant correlation with neurologically favorable survival (OR $=0.79 ; 95 \% \mathrm{CI}=0.31-2.02 ; \mathrm{p}=0.0414)$, but a significantly negative association with survival discharge $(\mathrm{OR}=0.40 ; 95 \% \mathrm{CI}=0.22-0.72 ; \mathrm{p}<0.0001)$. Table 4 presents the result of the logistic regression analysis of variables according to initial serum potassium level on survival outcomes.

\section{Discussion}

We conducted an observational study using a multicenter, prospective-collected database to evaluate initial serum potassium level as a predictor of OHCA. This study demonstrated that hypokalemia at ED arrival is associated with good neurological outcome and survival discharge in OHCA patients. Moreover, hyperkalemia at ED arrival is associated with poor survival discharge in OHCA patients. Therefore, the initial serum potassium level is likely to be used as a prediction marker of survival outcome in patients with OHCA.

This study demonstrated an increasing tendency of median age of the OHCA patients as potassium level increased, and that the rate of prehospital shockable rhythm inversely decreased as potassium level increased. Therefore, this study identified that the cardiac arrest in the hypokalemia group had higher rates of ventricular tachycardia (VT) or ventricular fibrillation (VF) arrest, which suddenly occurred at a younger age, and the cardiac arrest in the hyperkalemia 
Table 3. Effect of initial serum potassium level on survival outcomes

\begin{tabular}{|c|c|c|c|c|c|c|c|c|c|}
\hline \multirow{2}{*}{ Parameter } & \multirow{2}{*}{$\begin{array}{c}\text { Total } \\
\mathrm{n}\end{array}$} & \multicolumn{2}{|c|}{ Outcome } & \multicolumn{3}{|c|}{ Unadjusted } & \multicolumn{3}{|c|}{ Adjusted* $^{*}$} \\
\hline & & $\mathrm{n}$ & $\%$ & OR & $95 \% \mathrm{Cl}$ & $\mathrm{p}$-value & OR & $95 \% \mathrm{Cl}$ & $p$-value \\
\hline \multicolumn{10}{|c|}{ Primary outcome: neurologically favorable survival } \\
\hline total & 913 & 41 & 4.5 & - & - & - & - & - & - \\
\hline hypokalemia & 46 & 12 & 26.1 & 5.87 & $(2.66-12.95)$ & $<0.001$ & 4.45 & $(1.67-11.91)$ & 0.0012 \\
\hline normokalemia & 370 & 21 & 5.7 & 1 & - & - & 1 & - & - \\
\hline hyperkalemia & 497 & 8 & 1.6 & 0.27 & $(0.12-0.62)$ & $<0.001$ & 0.79 & $(0.31-2.02)$ & 0.0414 \\
\hline \multicolumn{10}{|c|}{ Secondary outcome: survival to discharge } \\
\hline total & 913 & 88 & 9.6 & - & - & - & - & - & - \\
\hline hypokalemia & 46 & 15 & 32.6 & 2.89 & $(1.46-5.72)$ & $<0.001$ & 2.25 & $(1.05-4.82)$ & 0.0011 \\
\hline normokalemia & 370 & 53 & 14.3 & 1 & - & - & 1 & - & - \\
\hline hyperkalemia & 497 & 20 & 4.0 & 0.25 & $(0.15-0.43)$ & $<0.001$ & 0.40 & $(0.22-0.72)$ & $<0.0001$ \\
\hline
\end{tabular}

* adjusted to age, gender, hypertension, diabetes mellitus, initial shockable rhythm, EMS defibrillation, arrest location, bystander CPR, arrest to arrival time, severe acidosis, renal insufficiency, and hypoxia. OR - odds ratio; 95\% Cl - 95\% confidence interval.

group had higher rates of non-shockable rhythm including pulseless electrical activity (PEA) and asystole, which occurred at an older age. This suggests that hypokalemia might have relatively caused VF at a young age, which is a possibility of causality of hypokalemia among young patients. This study also showed that the serum creatinine level gradually increased as the potassium level increased; therefore, we are able to assume that chronic kidney disease (CKD) as an underlying disease was also more prevalent in the hyperkalemia group. However, there was no significant difference in hypertension prevalence among the groups, and DM was more prevalent in patients with hypokalemia and hyperkalemia than in normokalemia. Based on these results, the elderly patients may have a higher rate of underlying diseases, including CKD, which can cause hyperkalemia. On the other hand, the occurrence of cardiac arrest in a private setting among the elderly might be susceptible to the development of hyperkalemia due to the relatively late discovery and treatment, as compared to the occurrence of cardiac arrest in a public setting among younger people, and the reduced prehospital shockable rhythm.

Hyperkalemia resulting from poor perfusion during cardiac arrest could be associated with poor survival outcome. Metabolic acidosis is commonly observed due to generalized poor-perfusion-induced lactic acidosis. Furthermore, hyperkalemia can be caused by extracellular shift during acidosis. In our study, the response time, scene time and transport time did not differ significantly among the 3 groups. However, the total arrest-to-ED-arrival time was significantly longer in the hyperkalemia group, while the hypokalemia group had a lower rate of witnessed cardiac arrest and a lower rate of such event occurring in a public location than the other groups. These conditions were associated with prolonged cardiac arrest time. Furthermore, the median ED arrival time in patients with cardiac arrest due to VF or VT among the hyperkalemia group was 32 min, which was 6 min longer than that of the patients with cardiac arrest due to VF or VT (26 min) among the normokalemia group. However, there was no statistical significance $(\mathrm{p}=0.06)$. This finding may be due to the longer prehospital time causing hyperkalemia, which could result in a different prognosis - even when the shockable rhythms were similar.

Hyperkalemia could result from underlying medical conditions, such as CKD, acute kidney injury or bleeding, or from medications, such as digoxin and potassiumsparing antihypertensive drugs. ${ }^{20}$ In our study, the hyperkalemia group had more elderly patients, a higher rate of DM and a higher median serum creatinine level. Previous studies showed a similar association with comorbidity and hyperkalemia in OHCA patients. ${ }^{21,22}$ As a result of the comorbidity and decreased physiological reserve in the elderly, the hyperkalemia group could have a negative association with survival outcome.

Hyperkalemia is known to cause conduction delay in the myocardium and fetal bradyarrhythmia. ${ }^{23}$ This could cause hyperkalemia to interrupt the electrical disturbance of the myocardium during a resuscitation effort ${ }^{24}$; thus, hyperkalemia could be associated with poor survival outcome. In addition, the correction of hyperkalemia may improve the survival outcome of the OHCA patients.

In our study, the hypokalemia group was associated with better neurological outcomes than the normokalemia group or the hyperkalemia group. As shown in Table 1, the hypokalemia group was relatively young and had higher rates of prehospital shockable rhythm, bystander CPR and public location, as well as a shorter time from the arrest to arrival at the ED. These factors are known to be good prognostic factors in prehospital cardiac arrest; therefore, the better results of the hypokalemia group might be due to them..$^{25,26}$

In the study population, the hypokalemia group had a more shockable rhythm. Among the 12 patients with good neurological outcome in the hypokalemia group, 
11 of them had a shockable rhythm. Previous studies show that hypokalemia is associated with an increased risk of arrhythmia in patients with cardiovascular disease (CVD). ${ }^{27,28}$ Therefore, the etiology of cardiac arrest due to hypokalemia was VT or VF, which was more reversible than the other causes of cardiac arrest. In addition, sudden cardiac arrest due to VT or VF is more likely to occur in a public setting in the patients' everyday life, ${ }^{29}$ which could result in a higher likelihood of receiving CPR from a bystander and a shorter arrest to ED time. Therefore, hypokalemia could be associated with survival outcome.

\section{Limitations}

This study was insufficient in the application of serum potassium level as a predictor of survival outcome in a prehospital setting because the patients with a successful prehospital ROSC, which is associated with good neurological outcome in a prehospital setting, were excluded. In addition, the serum potassium level at the time of the cardiac arrest may differ from the serum potassium level at ED arrival.

This study had several limitations. Firstly, this was an observational study, not a randomized controlled study. In order to adjust for the potential confounders, we used a multivariate logistic regression model including potential confounders. Secondly, the initial serum potassium level was not blinded, and data on whether hyperkalemia or hypokalemia was corrected therapeutically was not collected. The correction of the potassium level could influence the survival outcome of OHCA patients. Thirdly, the CAPTURES registry did not record data on history of CKD or a specific list of the current medical history, such as whether the patient has taken hypokalemia-inducing or hyperkalemia-inducing antihypertensive drugs. These drugs, whether the hypertension is hypokalemiainduced or not, are known to affect the serum potassium level and survival outcome of OHCA patients. ${ }^{24}$ In order to adjust for CKD history, we defined renal insufficiency as a serum creatinine level of more than $1.5 \mathrm{mg} / \mathrm{dL}$. We also adjusted for history of hypertension with whether the patient was using a hypertensive drug or not. Finally, although a previous history of CVD in the course of previous medical history is an important prognostic factor, this registry did not include CVD history but only a CKD history, such as DM and hypertension. Therefore, the analysis of such information was not possible.

\section{Conclusions}

In OHCA patients, the initial serum potassium level had a significant association with survival outcome. This study showed that hypokalemia had a significant association with good neurological outcome and survival discharge, while hyperkalemia had a negative correlation with survival discharge. These findings suggest that initial serum potassium level is associated with the etiology and result of cardiac arrest. Thus, initial serum potassium level can be used as a prediction marker of survival outcome in patients with $\mathrm{OHCA}$.

\section{References}

1. Berdowski J, Berg RA, Tijssen JG, Koster RW. Global incidences of outof-hospital cardiac arrest and survival rates: Systematic review of 67 prospective studies. Resuscitation. 2010;81(11):1479-1487.

2. Mozaffarian D, Benjamin EJ, Go AS, et al; American Heart Association Statistics Committee; Stroke Statistics Subcommittee. Heart disease and stroke statistics - 2015 update: A report from the American Heart Association. Circulation. 2015;131(4):e29-e322.

3. Iwami T, Nichol G, Hiraide A, et al. Continuous improvements in "Chain of Survival" increased survival after out-of-hospital cardiac arrests: A large-scale population-based study. Circulation. 2009;119(5):728-734.

4. Ahn KO, Do Shin S, Suh GJ, et al. Epidemiology and outcomes from non-traumatic out-of-hospital cardiac arrest in Korea: A nationwide observational study. Resuscitation. 2010;81(8):974-981.

5. Eisenberg MS, Cummins RO, Larsen MP. Numerators, denominators, and survival rates: Reporting survival from out-of-hospital cardiac arrest. Am J Emerg Med. 1991;9(6):544-546.

6. Pepe PE, Levine RL, Fromm RE Jr, Curka PA, Clark PS, Zachariah BS. Cardiac arrest presenting with rhythms other than ventricular fibrillation: Contribution of resuscitative efforts toward total survivorship. Crit Care Med. 1993;21(12):1838-1843.

7. Weston CF, Wilson RJ, Jones SD. Predicting survival from out-of-hospital cardiac arrest: A multivariate analysis. Resuscitation. 1997;34(1): 27-34.

8. Böttiger BW, Möbes S, Glätzer R, et al. Astroglial protein S-100 is an early and sensitive marker of hypoxic brain damage and outcome after cardiac arrest in humans. Circulation. 2001;103(22):2694-2698.

9. Fogel W, Krieger D, Veith $M$, et al. Serum neuron-specific enolase as early predictor of outcome after cardiac arrest. Crit Care Med. 1997; 25(7):1133-1138.

10. Callaway CW, Donnino MW, Fink EL, et al. Part 8: Post-Cardiac Arrest Care 2015 American Heart Association Guidelines Update for Cardiopulmonary Resuscitation and Emergency Cardiovascular Care. Circulation. 2015;132(18 Suppl 2):S465-S482.

11. Cohen JG, Boue Y, Boussat B, et al. Serum potassium concentration predicts brain hypoxia on computed tomography after avalancheinduced cardiac arrest. Am J Emerg Med. 2016;34(5):856-860.

12. Su Y-J, Lai Y-C. Optimal parameters for return of spontaneous circulation in resuscitating out-of-hospital cardiac arrest patients. Int J Gerontol. 2009;3(2):96-100.

13. Choi JS, Kim YA, Kim HY, et al. Relation of serum potassium level to long-term outcomes in patients with acute myocardial infarction. Am J Cardiol. 2014;113(8):1285-1290.

14. Patel RB, Tannenbaum S, Viana-Tejedor A, et al. Serum potassium levels, cardiac arrhythmias, and mortality following non-ST-elevation myocardial infarction or unstable angina: Insights from MERLIN-TIMI 36. Eur Heart J Acute Cardiovasc Care. 2017:6(1):18-25.

15. Ro YS, Shin SD, Song KJ, et al; Cardiac Arrest Pursuit Trial with Unique Registry and Epidemiologic Surveillance (CAPTURES) investigators. Risk of diabetes mellitus on incidence of out-of-hospital cardiac arrests: A case-control study. PLoS One. 2016;11(4):e0154245.

16. Ro YS, Shin SD, Song KJ, et al. Interaction effects between hypothermia and diabetes mellitus on survival outcomes after out-of-hospital cardiac arrest. Resuscitation. 2015;90:35-41.

17. Kim MJ, Ro YS, Shin SD, et al. Association of emergent and elective percutaneous coronary intervention with neurological outcome and survival after out-of-hospital cardiac arrest in patients with and without a history of heart disease. Resuscitation. 2015;97:115-121.

18. Neumar RW, Otto CW, Link MS, et al. Part 8: Adult advanced cardiovascular life support. Circulation. 2010;122(18 Suppl 3):S729-S767.

19. Jacobs I, Nadkarni V, Bahr J, et al; International Liaison Committee on Resuscitation; American Heart Association; European Resuscitation Council; Australian Resuscitation Council; New Zealand Resuscitation Council; Heart and Stroke Foundation of Canada; InterAmerican Heart Foundation; Resuscitation Councils of Southern Africa; 
ILCOR Task Force on Cardiac Arrest and Cardiopulmonary Resuscitation Outcomes. Cardiac arrest and cardiopulmonary resuscitation outcome reports: Update and simplification of the Utstein templates for resuscitation registries. A statement for healthcare professionals from a task force of the international liaison committee on resuscitation (American Heart Association, European Resuscitation Council, Australian Resuscitation Council, New Zealand Resuscitation Council, Heart and Stroke Foundation of Canada, InterAmerican Heart Foundation, Resuscitation Council of Southern Africa). Resuscitation. 2004;63(3):233-249.

20. An JN, Lee JP, Jeon HJ, et al. Severe hyperkalemia requiring hospitalization: Predictors of mortality. Crit Care. 2012;16(6):R225.

21. Lin C-H, Tu Y-F, Chiang W-C, Wu S-Y, Chang Y-H, Chi C-H. Electrolyte abnormalities and laboratory findings in patients with out-ofhospital cardiac arrest who have kidney disease. Am J Emerg Med. 2013;31(3):487-493.

22. Wissenberg M, Folke F, Hansen CM, et al. Survival after out-of-hospital cardiac arrest in relation to age and early identification of patients with minimal chance of long-term survival. Circulation. 2015:131(18): 1536-1545.
23. Ettinger PO, Regan TJ, Oldewurtel HA, Khan MI. Ventricular conduction delay and asystole during systemic hyperkalemia. Am J Cardiol. 1974;33(7):876-886.

24. Niemann JT, Cairns CB. Hyperkalemia and ionized hypocalcemia during cardiac arrest and resuscitation: Possible culprits for postcountershock arrhythmias? Ann Emerg Med. 1999;34(1):1-7.

25. Swor RA, Jackson RE, Tintinalli JE, Pirallo RG. Does advanced age matter in outcomes after out-of-hospital cardiac arrest in communitydwelling adults? Academic Emerg Med. 2000;7(7):762-768.

26. Sasson C, Rogers MA, Dahl J, Kellerman RL. Predictors of survival from out-of-hospital cardiac arrest: A systematic review and metaanalysis. Circ Cardiovasc Qual Outcomes. 2010;3(1):63-81.

27. Kjeldsen K. Hypokalemia and sudden cardiac death. Exp Clin Cardiol. 2010;15(4):e96-e99.

28. Alharbi FF, Souverein PC, de Groot MCH, et al. The impact of serum potassium-influencing antihypertensive drugs on the risk of outof-hospital cardiac arrest: A case-control study. Br J Clin Pharmacol. 2017;83(11):2541-2548.

29. Litwin PE, Eisenberg MS, Hallstrom AP, Cummins RO. The location of collapse and its effect on survival from cardiac arrest. Ann Emerg Med. 1987;16(7):787-791. 